Increasing Community Recycling with Persuasive Communication and Public Commitment Shawn M. Burn and Stuart Oskamp

Persuasive communication and public commitment were used to encourage recycling in a citywide program. The persuasive communication was a combination of factors which have been found by laboratory researchers to produce attitude and/ or behavior change. The public commitment manipulation involved signing a statement supportive of recycling. Households which did not recycle during a 6week baseline period were selected for experimental study. Trained Boy Scouts made an oral informational statement and then gave each of 201 experimental households one of three treatments (a written persuasive communication, public commitment, or both). A control group of 132 homes received no treatment. Recycling was observed for 6 weeks following delivery of all treatments. Results indicated that the three treatment groups recycled significantly more than the control group but did not differ significantly from each other. Future directions for applied work in this domain are discussed.

Americans generate over 150 million tons of trash per year at an average annual cost of \$4 billion. This is enough trash to fill the Superdome in New Orleans twice every day (Purcell, 1981). The lifetime garbage of a typical American will equal at least 600 times his or her adult weight (Hayes, 1978).

Finding land for waste disposal sites near urban areas is becoming increasingly difficult. For example, if present trends continue, nearly all of Los Angeles County will be without refuse disposal capacity by 1991 (California Solid Waste Management Board, personal communication, 1981).

Recycling, the reuse of wastes to produce useful commodities, could significantly contribute to the alleviation of the waste problem. The advantages of recycling are great. First, recycling diverts waste from landfills. This is epecially important as the areas for landfill purposes decrease, and of course there are clearly more desirable uses for land. Second, minerals and other raw materials are becoming scarcer and more expensive, and recycling extends resource supplies while typically rendering significant savings in both money and energy. For example, the recycling of aluminum saves over $95 \%$ of the energy needed to produce aluminum from bauxite ore and results in substantially less pollution of air and water (Hill, 1977).

The research reported here focused specifically on persuasive communications and public commitment as factors encouraging citizen participation in recycling programs_-programs designed to be beneficial to both the environment and the community.

\title{
Research Background
}

Past research by psychologists in the area of recycling has been mostly by behaviorists and thus has often emphasized the use of extrinsic incentives (usually in the form of money, toys, or raffles) to encourage participation (e.g., Geller, Chaffee, \& Ingram, 1975; McDermott, 1980). This has led to the implication that incentives are necessary to stimulate and maintain recycling (Geller, Winett, \& Everett, 
1982). However, some research suggested that once incentives are taken away the behavior is likely to extinguish (Couch, Garber, \& K arpus, 1979; Luyben \& Bailey, 1979; for a more extensive discussion, see Pardini \& Katzev, 1983-84), and in practical terms, it would be difficult to provide meaningful incentives for every pro-ecological behavior. Though much of the research aimed at increasing recycling has focused on the use of material incentives, it is likely that other approaches for increasing the longterm performance of pro-environmental behaviors may be developed through the use of socialpsychological principles.

Persuasive communication is another possible way to stimulate ecologically responsible behaviors, and one that is relatively inexpensive and easy to administer. Persuasive communication has been used with considerable success in the psychological laboratory (Hovland, Janis, \& Kelley, 1953; Leventhal, 1970), and factors found by researchers to increase persuasibility often appear in advertisements for commercial products. Recent work on persuasion has focused on the active processing of the information contained in a communication and the motivation of the individual to process it (Petty \& Cacioppo, 1981). It is thought that when a person processes the persuasive message, a number of issuerelevant beliefs are generated that may support the advocated position or may oppose it (Petty, Ostrom, \& Brock, 1981). To the extent that a positive evaluation results, persuasion is expected to occur.

Many of the factors found to increase persuasibility fit readily into this information-processing framework. Cook and Berrenberg (1981) noted that the impact of persuasive communications may be reduced if the recommended changes deviate too far from existing beliefs and practices. Great discrepancies between the individual's beliefs and those advocated by a communication are likely to reduce attention to the message in addition to contributing to the generation of opposing thoughts. Other research suggests that the effectiveness of persuasive communications advocating pro-ecological behaviors may be enhanced by the inclusion of information from reference groups relevant to the individual (McGuiness, Jones, \& Cole, 1977; Stern \& Kirkpatrick, 1977).

Petty and Cacioppo (1981) have argued that issue involvement increases a person's motivation to process a persuasive message. Involvement may be increased by emphasizing potential noxious consequences in the individual's life, or by a personalized communication in the form of face-to-face contact.

Another consideration in using persuasive communications is that their impact depends upon the credibility (expertise and objectivity) of the source of the communication (Eagly \& Chaiken, 1975). There also appears to be a relationship between fear arousal and persuasion (Hass, Bagley, \& Rogers, 1975; Higbee, 1969; Leventhal, 1970). Rogers (1975) proposed that the important aspects of a fear appeal are the magnitude of noxiousness of the depicted event, the conditional probability that the event will occur if no adaptive behavior is performed, and the perceived efficacy of the recommended coping responses in averting the danger. Thus, in designing a communication utilizing fear appeals, an attempt should be made to emphasize the personal relevance of the noxious event and the effectiveness of recommended actions in reducing the threat. Because the individuals may feel that their own ecologically responsible actions will have little impact unless similar actions are taken by others, the persuasive message should include information suggesting that others are performing the desired behavior (thus increasing the perceived efficacy of the behavior). Other research suggests that the degree of specificity 
of a recommended action is as important as the level of fear (Leventhal, Singer, \& Jones, 1965). Thus, fear appeals should be delivered by a credible information source accompanied by the suggestion of specific action.

Recycling appears to be a suitable candidate for the effective use of persuasive messages due to its relatively apolitical nature, unequivocal beneficial effects (a plausible argument for the harmful consequences of recycling cannot be easily made), and its general social acceptance. Furthermore, recycling does not typically run counter to existing beliefs. Arguments for recycling may also be easily structured to include those aspects of fear appeals suggested by Rogers (1975) to be important in persuasion; waste problems are easily depicted as noxious, and without recycling efforts, the capacity to dispose of waste is expected to be exceeded. In the present study it was hypothesized that, if carefully structured, persuasive communications may be influential in increasing recycling. Such careful structure refers to the combining of the factors mentioned above to increase persuasibility, rather than the testing of a single persuasive factor.

Another promising behavior-change technique is public commitment. Halverson and Pallak (1978) argued that manipulation of commitment can raise issue involvement and, as mentioned above, such involvement may increase a person's motivation to process a persuasive communication. It appears that attitudes stated publicly are relatively stable (unlikely to change) and that public expression of attitudes increases the performance of behaviors consistent with them (Kiesler, Mathog, Pool, \& Howenstine, 1971; Pallak, Cook, \& Sullivan, 1980). Typically, public commitment studies involve assessment of a particular attitude, having people sign some sort of statement or petition supportive of the desired issue position, and the assessment of attitudes and relevant behavior after signing. Arbuthnot, Tedeschi, Wayner, Turner, K ressel, and Rush (1976-77) found that, when combined with previous requests for action, compliance with a request to write city representatives in support of expanded city recycling programs dramatically increased compliers' use of recycling facilities. More recently, Pardini and Katzev (1983-84) successfully used public commitment to increase newspaper recycling. H owever, as Stern and Gardner (1981) point out, public commitment approaches may be hard to implement on a large scale because they depend upon personal contact with individuals. To counteract this problem, the use of volunteers such as Boy or Girl Scouts, church groups, etc., may be a way to apply that technique successfully.

\section{Method}

This research focused on participation in a city-sponsored recycling program. Trained Boy Scouts went to households selected for study, first making an oral informational statement regarding recycling and then administering treatments consisting of a persuasive communication, public commitment, or both. It was expected that the Boy Scouts would be a credible source of information since they are commonly associated with honesty and a concern for nature. In the informational statement, which was the same for all three treatment conditions, the scout introduced himself, cited some advantages of recycling, and described how to recycle with the city program.

The persuasive communication was a written appeal that householders were asked to read, containing components of normative social information, accepted beliefs and practices, moderate fear, 
and specific action suggestions. The normative social information supporting recycling included the following statements: "CLAREMONT IS RECYCLING. Recycling makes a difference and recycling is happening. Over $80 \%$ of Claremonters favor the City's recycling program, and other cities are calling to ask us how Claremont does it." To link the recommendations to accepted beliefs and practices, the written communication associated recycling with patriotic behavior and described the similarity of recycling to taking out the trash. The moderate-fear component of the communication consisted of the following rather graphic depiction: Californians alone produce some 40 million tons of refuse a yearenough to fill a two-lane highway, 10 feet deep from Oregon to the Mexican Border.

Currently, the average person in the United States produces about 1,300 lbs. of municipal solid waste a year. Most of this trash goes into landfills, and it is estimated that if present trends continue, nearly all of Los Angeles County will be without refuse disposal capacity by 1991 (only 8 years away).

The specific action component consisted of the statement: RECYCLING IS EASY . SIMPLY PUT NEWSPAPER, ALUMINUM, AND GLASS INTO SEPARATE BAGS AND PLACE AT THE CURB ON YOUR REGULAR TRASH COLLECTION DAY. (Note: Readers may obtain a copy of the intervention materials from the authors.)

The public commitment treatment consisted of a pledge card and sticker, which were given by the scout to selected households. The printed card stated, "I, , pledge support for Claremont's Recycling Program. I will help win the war on waste!" The recycling sticker was printed with an attractive logo and the words, "I Recycle to Win the War on Waste." This pledge card and sticker were given by the scout to selected households. Signing the card constituted the public commitment, with the sticker serving as a reminder of the commitment to recycle.

\section{Treatment Conditions}

There were three treatment conditions in this experiment. The Persuasive Communication condition included the brief oral informational statement and the written persuasive communication. The Public Commitment condition included the oral informational statement, presentation of the recycling pledge card, and the recycling sticker. The Combined treatment condition included all of the above. All three treatments were terminated with an offer of special recycling bags. The control group received no experimental treatment.

\section{Subjects}

Five separate city areas, judged relatively typical by a knowledgeable city official, were selected for observation. Prior to any intervention, the placement of recyclables at the curb on trash collection day was recorded over a 6-week period for the 750 households in the selected areas. The 541 households which did not recycle at all during the 6-week baseline period were selected for experimental study. One-fourth of the nonrecycling households in each area were assigned to each of the study conditions, resulting in approximately 135 households per group. Each of the five city areas was further subdivided into neighborhoods characterized by high, medium, or low recycling. Within each such neighborhood, the same treatment condition was assigned to three or four closely spaced nonrecycling homes, the next three or four homes received a different treatment, and so on. 
Of the 409 households selected for intervention (excluding the controls), there were $28 \%$ where no one could be contacted after three personal visits; at 16\% of the households the person contacted claimed that they already recycled and thus they were dropped from the treatment conditions; and 6\% of the visited homes refused participation and did not receive any treatment. A total of 201 homes ultimately received one of the treatments: 77 in the Persuasive Communication condition, 62 in the Public Commitment condition, and 62 in the Combined condition. The numerical differences in the four groups were not due to differences in the treatment conditions themselves since in all cases refusals took place before, during, or immediately following the oral informational statement and prior to delivery of any of the distinctive components of each treatment condition. The control group receiving no treatment included the 132 households originally selected.

\section{Procedure}

Ten Boy Scouts between the ages of 13 and 17 delivered the treatments. They were trained over the course of three sessions that involved taking turns reading aloud a paper stressing the need for recycling and the possible contribution of the Boy Scouts. This was followed by role-playing, rehearsal, and delivery of treatments to a few trial homes in neighborhoods not included in the study. All Boy Scouts were trained to deliver all treatments but were blind as to the research hypotheses.

The Boy Scouts were assigned to teams of three scouts and each team was assigned to several consecutive streets within the same area of the city. To avoid possible confusion between the treatment elements, a scout would deliver only one treatment to all homes he was assigned on a given street and the researcher directed him to rehearse his treatments before being dropped off in the target neighborhood.

Visits were made on Saturday and Sunday afternoons and one weekday evening, with up to two additional callbacks being made to not-at-homes. Each scout was given forms that clearly designated the treatment for each address and included a checklist on which to report acceptance or refusal of each treatment component at each home (e.g., accept communication, sign card, accept sticker, accept recycling bags, comments). The experimenter stayed in a central location most of the time, occasionally circling the area to check on progress, answer scouts' questions, and insure that all was going smoothly.

For each of the 6 weeks following delivery of the last treatment, recycling was again observed for all 753 households. The research observer was a city official who was blind as to the experimental condition for a residence when recording recycling. A simple dichotomous score was assigned each week indicating whether or not there were recyclables at the curb in front of the house, and these scores were summed to indicate frequency of recycling.

\section{Results}

Eighty-two (41\%) of the 201 homes which received experimental treatments recycled at least once in the 6 weeks of observation following treatment. In the Persuasive Communication condition, 39\% of the homes began recycling; Public Commitment condition, 42\% began recycling; and in the Combined condition, $42 \%$ of the households recycled at least once during the posttreatment data collection. Of the 132 control homes, only $11 \%$ began recycling (Table 1 ). 
Approximately half of the households originally slated for treatment did not receive an experimental treatment due to absence, refusal, or claims that they already recycled. Of the households which claimed they already recycled, $16 \%$ recycled at least once in the 6-week period following contact (11 out of 67). Three of the 26 households that refused treatment recycled in the posttreatment period (11\%), while 11 of the 114 not-at-home households recycled (9.6\%). The occurrence of refusals was not significantly related to the area of the city $(\mathrm{X} 2=2.79, \mathrm{df}=4, \mathrm{p}>.05)$, nor were not-at-homes $(\mathrm{X} 2=3.28$, $\mathrm{df}=4, \mathrm{p}>.05)$.

An analysis of variance was conducted to compare the three treatment groups and the control group in the number of weeks each household recycled (scores ranging from 0 to 6 ). The four groups differed significantly; $\mathrm{F}(3,329)=11.30, \mathrm{p}<.001$. The means for these groups were: communication .844; commitment 1.129; combined 1.065; and control .174. An a posteriori Tukey HSD test showed that all three treatment groups differed significantly $(\mathrm{p}<.05)$ from the control group in the number of times that they recycled but did not differ significantly from each other. It should be noted that treatments did not vary in effectiveness according to area of city, $\mathrm{F}(8,186)=.653$.

It is conceivable that those homes which ultimately received treatments could have been systematically different in some way from the total experimentally designated treatment groups. In order to examine the possibility of a selection bias due to the high rate of erosion from the original treatment groups, all households originally slated for any of the three treatments (households that claimed they already recycled, not at homes, and refusals) were combined with the actual treatment group. This total group was then compared with the control group in a very conservative test of treatment effects as suggested by Cook and Campbell (1979). An analysis of variance indicated that there was still a highly significant difference in frequency of recycling between the total originally designated treatment group and the control group; $\mathrm{F}(1,539)-13.280, \mathrm{p}<.001$.

In order to examine the strength of the experimental effect, a comparison was made between the group composed of those that recycled at least once in the baseline period (those who recycled during the baseline and therefore did not receive treatment), and the subgroup of experimentally treated homes that began recycling after receiving treatment. The average number of weeks that those treated homes recycled was 2.45 , while for previous baseline recycles it was 2.44 weeks. The lowest incidence of recycling for the experimentally treated homes was in the first week of the posttreatment period. As may be seen in Table 1, for the remaining 5 weeks, levels of recycling in all three treatment groups remained relatively stable rather than showing a noticeable decline as the posttreatment period progressed.

\section{Discussion}

The large difference between the recycling of the experimentally treated homes and the control group is very encouraging. This finding looks even stronger when the inevitable differences in treatment implementation are taken into account. For example, scouts undoubtedly varied in their treatment delivery in spite of training, and households varied in their receptiveness toward an unanticipated message. In addition, competing demands for subjects' attention, such as television or household tasks, could not be controlled for. Also, scouts were instructed to speak only to adults, but their contact was not necessarily the individual responsible for taking out the trash. However, as is characteristic of field 
studies, any such losses in internal validity should be accompanied by increases in external validity (Cook \& Campbell, 1979). In other words, similar results could probably be obtained by other cities and organizations using techniques along the lines of those used in this study.

The finding of no significant difference among the three treatments in the face of such a strong overall treatment effect could be due to several factors. For one, components shared by all three treatments, such as face-to-face contact and information about how to recycle, could have been responsible for their comparable effects. All three treatments may also have made salient any existing prorecycling attitudes and reminded citizens of their intentions to recycle. If these were their main effects, treatments would not be expected to have differing results, and this may also explain why the more intensive combined treatment was not more effective than the others. It is also possible that the lack of differential treatment effects may have been due to the limited range of outcome scores (ranging from 0 to 6 ) that resulted from the short data collection period. A longer posttreatment data collection would have been desirable in order to trace the strength and duration of the treatment effect, but the investigators' time and resources did not permit this.

The recycling of the treated homes did not appear to be a temporary experimental effect, however, for the rate of recycling appeared to hold steady as the 6-week posttreatment period progressed. While the first week following treatment had a somewhat lower incidence of recycling, this seems logical given the short time that had passed in which to collect recyclables. The fact that it was also true for the baseline recyclers suggests that it may have been related to external factors such as weather conditions. Another encouraging finding was that the frequency of recycling by the treated homes that began recycling was quite similar to that of the baseline recyclers.

\section{Future Directions}

Although actions to alleviate environmental problems are often delayed until a crisis is imminent, research on how to stimulate resource-efficient behaviors remains important. The psychological literature on environmentally responsible behaviors is quietly growing, but it remains largely exploratory and its growth has slowed considerably as public concern about the energy crisis has waned. This study successfully increased participation in a city-sponsored recycling program by using persuasive communication and public commitment. However, more studies in this area are needed.

The use of carefully constructed persuasive communications in the field without personal contact should be examined because of the potential for easy application. It is possible that some of the benefits of face-to-face contact could be attained by personalized addressing (in contrast to "dear occupant"), and an attractive, professional communication. These features have been found to increase response rates for survey questionnaires (Dillman, 1978) and might similarly increase attention to, and subsequent comprehension of, persuasive messages.

Normative factors affecting pro-environmental behaviors also require further study. The perceived social desirability of an action may conceivably increase the probability of its performance. Perceived group norms advocating a behavior may make the possibility of its performance more salient or may suggest that the action is more likely to make a difference. Nielsen and Ellington's (1983) study showing the significant effect of block leaders on recycling is illustrative in this regard. 
Lastly, some general guidelines may be of use to psychologists desiring to increase proenvironmental behaviors. The tremendous variability of people and environments will make it difficult for field researchers to be sure what measures will be effective in creating change. Practical considerations, such as the preferences of city administrators, funding, or other organizational constraints, will also unavoidably influence the behavior-change techniques taken by applied researchers. Selection biases, resulting from unexpected attrition and affecting the comparability of treatment and control groups, will be a source of unwanted noise in experimental designs. Consequently, a general and flexible commitment to solving environmental problems, rather than to a particular technique for solving them, is likely to meet with more success in field settings.

\section{References}

Arbuthnot, J., Tedeschi, R., Wayner, M., Turner, J., Kressel, S., \& Rush, R. (1976-77). The induction of sustained recycling through the foot-in-the door techniques. Journal of Environmental Systems, 6, 353-366.

Cook, S. W., \& Berrenberg, J. L. (1981). Approaches to encouraging conservation behavior: A review and conceptual framework. Journal of Social Issues, 37,73-107.

Cook, T. D., \& Campbell, D. T. (1979). Quasi-experimentation: Design \& analysis for field setting. Chicago: Rand McNally.

Couch, J. V., Garber, T., \& Karpus, L. (1979). Response maintainence and paper recycling. Journal of Environmental Systems, 8, 127-137.

Dillman, D. A. (1978). Mail and telephone surveys. New York: Wiley.

Eagly, A. H., \& Chaiken, S. (1975). An attribution analysis of the effect of communicator characteristics on opinion change: The case of communicator attractiveness. Journal of Personality and Social Psychology, 32, 136-144.

Geller, E. S., Chaffee, J. L., \& Ingram, R. E. (1975). Promoting paper recycling on a college campus. Journal of Environmental Systems, 5, 39-57.

Geller, E. S., Winett, R. A., \& Everett, P. B. (1982). Preserving the environment: New strategies for behavior change. New York: Pergamon. Halverson, R. R., \& Pallak, M. S. (1978). Commitment, ego-involvement, and resistance to attack. Journal of Experimental Social Psychology, 14, 1-12.

Hass, J. W., Bagley, G. S., \& Rogers, R. W. (1975). Coping with the energy crisis: Effects of fear appeals upon attitude toward energy consumption. Journal of Applied Psychology, 60, 754-756.

Hayes, D. (1978). Repairs, reuse, recycling-First steps toward a sustainable society. (World Watch Paper 23) Washington, DC: Worldwatch Institute.

Higbee, K. (1969). Fifteen years of fear arousal: Research on threat appeals, 1953-1968. Psychological Bulletin, 72, 426-444.

Hill, D. (1977, September 4). Fighting over scraps. Washington Post.

Hovland, C. I., Janis, I. L., \& Kelley, H. H. (1953). Communication and persuasion. New Haven, CT: Yale University Press.

Kiesler, C. A., Mathog, R., Pool, P., \& Howenstine, R. (1971). Commitment and the boomerang effect: A field study. In C. Kiesler (Ed.), The psychology of commitment: Experiments linking behavior 
to belief (pp. 74-85). New York: Academic Press.

Leventhal, H. (1970). Findings and theory in the study of fear communications. In L. Berkowitz (Ed.), Advances in experimental social psychology (Vol. 5). New York: Academic Press.

Leventhal, H., Singer, R., \&Jones, S. (1965). Effects of fear and specificity of recommendation upon attitudes and behavior. Journal of Personality and Social Psychology, 2, 20-29.

Luyben, P. D., \& Bailey, J. S. (1979). Newspaper recycling: The effects of rewards and proximity of containers. Environment and Behavior, 11, 539-557.

McDermott, J. (1980). Recycling: New answers to NYC's big problem. Journal of Appropriate Technology, 1, 9-10.

McGuiness, J., Jones, A. P., \& Cole, S. G. (1977). attitudinal correlates of recycling behavior. Journal of Appled Psychology, 62, 376-384.

Nielsen, J. M., \& Ellington, B. L. (1983). Social processes and resource conservation: A case study in low technology recycling. In N. R. Feimer \& E. S. Geller (Eds.), Environmental psychology: Directions and perspectives. New York: Praeger.

Pallak, M. S., Cook, D. A., \& Sullivan, J. J. (1980). Commitment and energy conservation. In L. Bickman (Ed.), Applied social psychology annual (Vol. 1, pp. 235-253). Beverly Hills, CA: Sage.

Pardini, A. U., \& Katzev, R. D. (1983-84). The effect of strength of commitment on newspaper recycling. Journal of Environmental Systems, 13, 245-254.

Petty, R. E., \& Cacioppo, J. T. (1981). Attitudes and persuasion: Classic and contemporary approaches. Dubuque, IA: Brown.

Petty, R. E., Ostrom, T. M., \& Brock, T. C. (1981). Historical foundations of the cognitive response approach to attitudes and persuasion. In R. E. Petty, T. M. Ostrom, \& T. C. Brook (Eds.), Cognitive responses in persuasion. Hillsdale, NJ: Erlbaum.

Purcell, A. H. (1981). The world's trashiest people: Will they clean up their act or throw away their future? The Futurist, 2, 51-59.

Rogers, R. W. (1975). A protection motivation theory of fear appeals and attitude change. Journal of Psychology, 91, 93-114.

Stern, P. C., \& Gardner, G. T. (1981). Psychological research and energy policy. American Psychologist, 36, 329-342.

Stern, P. C., \& Kirkpatrick, E. M. (1977). Energy behavior: Conservation without coercion. Environment, 10, 10-15. 
Table 1

Percentage of Homes Recycling After Treatment

\begin{tabular}{|c|c|c|c|c|c|c|c|c|c|}
\hline Condition & $\mathrm{N}$ & Overall & Week 1 & Week 2 & Week 3 & Week 4 & Week 5 & Week 6 & $\begin{array}{c}\text { Weekly } \\
\text { mean }\end{array}$ \\
\hline Communication & 77 & $39 \%$ & $10.4 \%$ & $18.2 \%$ & $15.6 \%$ & $11.7 \%$ & $15.6 \%$ & $13.0 \%$ & $15.0 \%$ \\
\hline Combined & 62 & $42 \%$ & $14.5 \%$ & $17.7 \%$ & $22.6 \%$ & $17.7 \%$ & $16.1 \%$ & $17.7 \%$ & $17.7 \%$ \\
\hline Commitment & 62 & $42 \%$ & $16.1 \%$ & $17.7 \%$ & $17.7 \%$ & $21.0 \%$ & $21.0 \%$ & $19.4 \%$ & $18.8 \%$ \\
\hline Control & 132 & $11 \%$ & $3.7 \%$ & $1.5 \%$ & $2.2 \%$ & $2.2 \%$ & $2.2 \%$ & $5.3 \%$ & $2.8 \%$ \\
\hline Baseline recyclers ${ }^{a}$ & 212 & $80.7 \%$ & $30.0 \%$ & $43.3 \%$ & $42.9 \%$ & $41.0 \%$ & $37.0 \%$ & $49.0 \%$ & $40.5 \%$ \\
\hline
\end{tabular}

${ }^{\mathrm{a}}$ Baseline recyclers recycled during the baseline and did not receive treatment. 